\title{
The German IVF Register as an Instrument to Document Assisted Reproductive Technologies
}

\author{
Das Deutsche IVF-Register als Instrument zur Dokumentation \\ der assistierten Reproduktionstechnologien
}

Authors

Affiliation
S. Kadi, U. Wiesing

Institut für Ethik und Geschichte der Medizin, Eberhard Karls Universität Tübingen, Tübingen
Deutsche Version unter: http://dx.doi.org/ $10.1055 / \mathrm{s}-0042-108576$

\section{Abstract \\ $\nabla$}

The German IVF Register (Deutsches IVF-Register [D.I.R]) has been collecting and publishing data on the use of IVF and related methods in Germany since 1982 . It is the only institution which provides information for all of Germany on procedures and their success rates. For this reason it plays an important role in the provision of information to the public, to patients, political decision-makers and the scientific community. However, the register does not have the data of all centers offering treatment in Germany nor does it have complete datasets on all reported treatments. The register accepts retrospective data entries, it does not publish the success rates of individual centers and up until 2015 it did not provide a summary of information which was suitable for non-specialists. The D.I.R has been the focus of criticism in the past. Even today, the information it provides to the scientific community, the public, political decision-makers and potential patients on the outcomes of assisted reproduction is insufficient. The documentation of reproductive medicine procedures in other countries is much more meaningful.

\section{Introduction}

\section{$\nabla$}

Any field of medicine which claims to be scientific is not only subject to the requirement that it helps the sick, it must also give an account of itself to the general public concerning the success of its efforts. It is not enough to simply want to help; the results of medical activities must also be collected, processed, documented, and evaluated. All fields of scientific medicine must explore whether and to what extent physicians are actually providing the envisaged help to their patients. All of the above also applies to reproductive medicine procedures.

\section{Zusammenfassung \\ $\nabla$}

Seit 1982 sammelt und publiziert das Deutsche IVF-Register (D.I.R) Daten zur Anwendung von IVF und angrenzenden Methoden in Deutschland. Als einzige Institution könnte es deutschlandweite Angaben zu den Verfahren und ihren Erfolgsquoten liefern. Aus diesem Grund kommt ihm bei der Information der Öffentlichkeit, der Patienten, politischer Entscheidungsträger und der Scientific Community eine wichtige Rolle zu. Das Register verfügt allerdings weder über die Daten aller in Deutschland behandelnden Zentren noch über vollständige Datensätze aller gemeldeten Behandlungen. Es lässt auch retrospektive Dateneingaben zu, veröffentlicht keine Erfolgsquoten einzelner Zentren und bis 2015 auch keine laienverständliche Zusammenfassung. Das D.I.R stand in der Vergangenheit bereits in der Kritik. Auch heute kann es die Scientific Community, die Öffentlichkeit, politische Entscheidungsträger und potenzielle Patientinnen nur unzureichend über die Ergebnisse der assistierten Reproduktion informieren. Die Dokumentation von reproduktionsmedizinischen Interventionen ist in anderen Ländern deutlich aussagekräftiger.

The German IVF Register (Deutsches IVF-Register [D.I.R]) has been documenting the use of IVF and related methods since 1982 , that is, since shortly after the first successful IVF procedures were carried out in Germany. The register analyzes results and publishes them in the form of annual reports. No other institution can provide information on procedures and their success rates for all of Germany. This article looks at the institutional anchoring of the D.I.R in Germany, together with the D.I.R's documentation of IVF and related methods. 


\section{The D.I.R as an Institution}

\section{$\nabla$}

The D.I.R was set up in 1982 as a voluntary association of IVF centers [1] and was approved as an institution of the German Society for Gynecology and Obstetrics in 1996 [2]. The Medical Association of the federal state of Schleswig-Holstein maintained and managed the register from the establishment of a national head office in 1996 until 2013 [3,4]. In 1998, a directive of the German Medical Association on how to carry out assisted reproduction proposed, for the first time, that the medical associations of the different German states should come together to establish a documentation center, which would be known as the German IVF Register (D.I.R) [5] (p. 3169). All centers without exception would be expected to provide data: "every working group should compile computer-based records in accordance with the questionnaire of the German IVF Register" [5] (p.3169). In actual fact, not all centers registered with the D.I.R [6]. In a non-public hearing of the select committee "Law and Ethics in Modern Medicine" of the German Bundestag held on 26th March 2001, the chair of the D.I.R at the time demanded "a 'federal office of reproductive medicine' following the British model 'to prevent uncontrolled proliferation' whose responsibilities would include the licensing of centers, the documentation of outcomes, and regular, unannounced inspections of the centers" [6] (p.54). However, this proposal was not implemented.

In 2009 the D.I.R was incorporated as a registered association based in Berlin. An association of this type is constitutionally not capable of pushing through the compulsory membership of all centers of reproductive medicine. From 2013 on, the Medical Association of Schleswig-Holstein no longer cooperated with the D.I.R [4]. In 2014, the (proposed) guideline was amended in such a way that from then on, data collection by the D.I.R was no longer recommended; instead, the medical association of each German federal state would be permitted to decide for itself where the data should be collected [7]. With this amendment, the D.I.R lost its status as a national data collection center. It nevertheless remains the only national register in Germany.

At present, there is no obligation for all centers of reproductive medicine in Germany to pass on their data to the D.I.R [8]. In addition, those centers which are official members of the D.I.R do not necessarily always supply complete datasets about the course of treatment or the course of pregnancy. Although the D.I.R now collects the data of one year in September of the following year, there are still considerable gaps in the datasets. And the next annual report does not fill these gaps either. In a special evaluation published in 2014, the D.I.R showed that even for pregnancies reported for 2012 , only an average of $84.9 \%$ of pregnancy outcomes were reported per center [9].

The regulations in the (proposed) guideline on the implementation of assisted reproductive technologies issued by the German Medical Association (German Medical Association 2006) also specify the type of documentation. According to the (proposed) guideline, data should only be collected prospectively. The D.I.R had already resolved to do this in 1997 [1]. The term "prospectively" was defined in such a way that data on the treatment cycle had to be recorded within eight days after starting hormone treatment. This means that the requirement is not for a "prospective" collection of data in the strictest sense of the term. Moreover, it cannot be precluded that all data is only entered after some delay. The following data should be reported: "homologous insemination following hormone stimulation, IVF with ET, GIFT, ICSI, heterologous insemination following hormone stimulation, heterologous IVF/ICSI, PBD, relating to: patient age, indications for the method, course of stimulation, number and fertilization rate for inseminated oocytes with IVF/ ICSI, number of transferred oocytes following GIFT, number of transferred embryos with IVF/ICSI, pregnancy rate, birth rate, miscarriages, ectopic pregnancies, abortions, rate of multiple births, malformations" [10] (p. 1398).

The requirement that only prospective data should be entered is well founded, because the temptation to manipulate data when data is collected retrospectively is well known. In 2004, Stammer et al. pointed out the differences in pregnancy rates following IVF for the year 1997, with mixed data resulting in a rate of $24.4 \%$ compared to a rate of $18.5 \%$ for exclusively prospective data [11]. Despite this known distortion, calculation of the baby takehome-rate (BTHR) for 2012 in the 2013 annual report is based on both prospective and retrospective data [9] (p. 14).

\section{The Definition of "Success" in a National Register $\nabla$}

The D.I.R not only publishes outcomes, it also sets standards. As the only national German register it is also involved in defining what should be considered a successful outcome in reproductive medicine. What should be decisive: is it the quality of the services offered in terms of supporting parents in dealing with a disorder [12]? Or is it the birth of a child or the inception of pregnancy? For the patient, inception of pregnancy is certainly not the crucial outcome. The success of reproductive medicine depends on the choice of criteria.

The rate of clinical pregnancy per embryo transfer which IVF centers also like to report on their websites [13] is, naturally, rather higher than the rate of live births. But for patients the rate of live births is what is important. However, there are also different ways of calculating rates of live births [14], for example, as a percentage of all initiated treatments or of all embryo transfers carried out. If only embryo transfers are included (live births divided by embryo transfers), then all treatments in which embryo transfer was not even attempted will be missing from the calculation (this corresponds to the calculations in the last report of the D.I.R [9]).

Cumulative live birth rates are another way of quantifying success. They reflect the cumulative success for the respective number of cycles carried out. But this figure depends on the willingness (and the opportunity) to undergo the respective number of treatment attempts. If a center reports a cumulative live birth rate, information on the percentage of patients who discontinued treatment at an earlier stage is indispensable. The analyses done by the D.I.R do not contain any cumulative live birth rates, but the D.I.R reports on the number of treatments carried out per woman from 1997 to 2013 [9] (p. 29). According to the figures of the D.I.R, more than $40 \%$ of women only underwent one treatment cycle, 15\% underwent 3 treatment cycles, fewer than 9\% underwent 4 treatment cycles, less than $5 \%$ had 5 cycles, and less than $1 \%$ had 10 cycles. 


\section{The D.I.R as a Source of Information for Patients} $\nabla$

Only the D.I.R is able to publish annual national data on the use of assisted reproductive technologies in Germany. This means that the D.I.R could play an important role in providing information to patients. Admittedly, the information would have to be processed in such a way that it would be both comprehensible and relevant for patients.

At present, the information does not meet either of these criteria. In 2015, an uncritical and much too short summary was appended to the main report for the first time [15]. Although the D.I.R does have the results for individual centers, it only publishes national data, but this data, as previously mentioned, is incomplete and some of the data was entered retrospectively. No information is given on the success rates for individual centers. According to the current articles of incorporation of the D.I.R, the "distribution or publication of data which would permit the identity of a center to be inferred [...] is prohibited" [16] (p. 5). German physicians working in reproductive medicine already demanded the publication of a national standard a few years ago [17] to help patients choose a center. The publication of standards is quite common in other countries. In the United Kingdom, for example, the authority which is responsible for managing the official register also publishes information on the results of individual centers [18]. For every center, patients can look at the probability of achieving a live birth when using a specific method for various age groups and compare the figure to the respective national average. The publications of the D.I.R do not provide this information.

\section{Results for Assisted Reproductive Technologies in Germany \\ $\nabla$}

The annual report categorizes the baby take-home-rate according to the method used; the figures for 2012 were $17.78 \%$ for IVF, $18.02 \%$ for ICSI, $22.09 \%$ for a combination of IVF/ICSI, and $12.58 \%$ for frozen embryo transfer [9] (p. 14, live births divided by treatments). The mean baby take-home-rate for all methods was therefore $17.62 \%$. However, the following should be kept in mind:

1. Despite an "integrated verification that the data are collected prospectively", which has been extolled as a "unique selling point of the German IVF register" [1], the calculation is based on both prospective and retrospective data. This does not comply with the resolution of the D.I.R from 1997 and the recommendation of the German Medical Association in 2006, according to which all treatment cycles should be recorded prospectively (defined as eight days after the start of hormone treatment at the latest).

2. Out of a total of 81035 reported treatments or 77368 plausible treatment cycles for 2012,2116 outcomes $(2.73 \%$ of the plausible treatment cycles) were still unknown in 2014, even though treatment was started in 2012 and the results must therefore have been known by September 18, 2014 [9] (p. 13). The percentage of pregnancy outcomes not recorded in 2014 per method ranges from $11 \%$ (IVF/ICSI) to $17 \%$ (IVF) of pregnancies. In addition, the D.I.R has reported two other higher baby takehome-rates [9] (p.14). In one version (A), cycles where the pregnancy outcome is unknown were not included in the calculations. In this case, the mean baby take-home-rate for all treatment methods was $18.33 \%$. In the second version (B), a "probable birth rate" was assumed [9] (p. 14) (births per pregnancy) for the cycles where the real outcome was unknown and this figure added to the number of known births. The mean baby take-home-rate for all treatment methods was then calculated as $20.14 \%$. Based on the reasonable assumption that unsuccessful treatment outcomes will be reported less often, both of the above versions probably result in outcomes that are too high.

3. The reported baby take-home-rates do not refer to all initiated cycles starting from the time of drug administration but start at a later stage of treatment. This means that treatment cycles which were unsuccessful or were terminated at an earlier stage (stimulation for egg collection, follicular puncture, oocyte retrieval, oocyte culture or preparation for frozen embryo transfer) are omitted [9] (p. 13). What does that mean? According to the D.I.R, the mean baby take-home-rate for all treatment methods is $17.62 \%$ (this equals the mean of the lowest reported baby take-home-rates for all methods used, live births for IVF, ICSI, IVF/ICSI) [9]. But if the mean baby take-home-rate is now calculated from the time of stimulation for oocyte retrieval or the time of preparation for frozen embryo transfer (and not simply from the time of transfer), the rate for 2012 would be $15.27 \%$ (births divided by plausible cycles). Moreover, the distortion due to the retrospective entry of data also needs to be taken into account.

The method chosen by the D.I.R to calculate the baby take-homerate thus suggests unrealistically high success rates. This subverts the premise of informed consent. Patients are already inclined to overestimate the prospects of IVF and related methods $[19,20]$. The publications by the D.I.R reinforce this tendency. It should be noted at this point that in 1988 the German Medical Association already stated that the then current success rate of $15 \%$ was in "urgent need of improvement" [21] (p. 36); today, some 27 years later, the success rate is still just $15 \%$.

\section{Conclusion}

$\nabla$

The D.I.R is the only register which aims to collect and publish data on the outcomes after IVF and related methods for all of Germany. These data are indispensable for a scientific evaluation of procedures, for political decisions on reproductive medicine, for the general public, and for patients. Without a proper knowledge of the real prospects, risks and burdens, patients cannot make an informed decision for or against specific treatment methods.

The success rates for IVF and related methods were low from the outset. The temptation to embellish them was correspondingly great. Already in 1985 Soules demanded greater honesty with regard to in vitro fertilization pregnancy rates [22]. To obtain meaningful data on the use of assisted reproductive technologies in Germany it will be necessary, as proposed by the German Medical Association in 2006, to collect prospective data about the overall course of all treatment cycles [10]. That is the only way to calculate and obtain reliable national data on outcomes for individual methods and age groups. The fact that not all centers participate in the D.I.R can rightly be described as a "scandal" [23] (p.52). Despite the important functions which the D.I.R could perform, its status remains insecure. Originally, it was developed as a voluntary association between IVF centers. Following a period in which the D.I.R was recognized and included in guidelines issued by the German Medical Association, the D.I.R lacks this recognition today. 
The data of the D.I.R is in many ways inadequate: firstly, only data from a selection of all centers located in Germany are recorded. Secondly, even when treatment cycles are documented, not all of the data for the cycles (including births) is reported to the D.I.R. Thirdly, the D.I.R still continues to use both prospective and retrospective data, even though guidelines and their own resolutions should prevent this. Retrospectively reported data are easier to manipulate and have been proven to produce unrealistically high success rates. Fourthly, the D.I.R does not publish outcomes for individual centers. Thus patients cannot obtain information the way they can in the United Kingdom, where success rates for individual clinics can be obtained from the website of the HFEA, the national UK regulator which monitors fertility clinics in the UK [18]. Fifthly: the presentation of results is completely unsuitable for non-specialists as it is too complicated. The summary for patients, published for the first time in 2015, is too short and, in addition, it is uncritical. The summary for patients does not give any information on outcomes for individual centers.

The data of the D.I.R creates unrealistic expectations about successful outcomes because it primarily shows the success rates for different stages in the procedure. The baby take-home-rate following stimulation is, of course, lower than the successful outcomes reported for individual stages. But only the lowest rate is relevant for the woman or couple. The individual stages are important for scientific research, but they are not suitable as an indicator to inform patients about the expected success rate. To sum up the issues with the presentation of outcomes: it is not just the quality of the published figures that is inadequate. If all data were entered prospectively under careful monitoring and the data were complete, this would represent a scientific achievement, but the data would still not necessarily be useful for patients. By proceeding in this way, science is taking itself and not the patient as the reference point of success [24]. But in doing so, medicine is distancing itself from its real job. The actual success rate of approximately $15 \%$ per treatment cycle in Germany is sobering, given the figures used to promote IVF (cf. [13]). The documentation and communication of outcomes following IVF or related reproductive medicine treatments was criticized from the outset (cf. $[25,26])$. The select committee of the German Bundestag commented in 2002 that not all centers in Germany passed on their data to the D.I.R [6]. This deficit also has an impact on political decision-making as policymakers do not have recourse to high quality data. Since the report of the select committee "Law and Ethics in Modern Medicine", the D.I.R has had 14 years to supply data of an acceptable quality. That has not yet happened.

For years, there have been demands that Germany should have a regulator of its own - similar to the British HFEA - which would also have a supervisory function (e.g. [27]). The committees of the various federal medical associations are currently working on new processes for quality management $[9$, for " $[t]$ he medical associations have decided to improve the existing quality management procedures for centers of reproductive medicine and favor a nationally coordinated advancement of quality in reproductive medicine across all of Germany whereby the new process would be differentiated more clearly from scientific issues and from any function as a register than was previously the case" [28] (2nd paragraph). It is, however, doubtful whether the new form of quality management will rectify the known deficiencies of the D.I.R. In an enlightened society it is unacceptable that no adequate information is available about such an important modern technology. If the self-governance of the medical profession is not able to provide this information, then a public authority or an institute under state supervision will be unavoidable.

Demanding a better documentation of success rates is by no means unrealistic as this requirement has already been implemented in other countries [29]. There are no convincing arguments why high quality, comprehensive documentation which would also be comprehensible to non-specialists is not possible in Germany.

\section{Acknowledgements}

\section{$\nabla$}

The authors would like to thank one of the anonymous reviewers for pointing out an opportunity for data manipulation during the transfer of data to the D.I.R, which was not previously known to them. They would additionally like to thank Prof. Dr. Dorothee Kimmich from the German Department of the University of Tübingen.

\section{Conflict of Interest \\ $\nabla$}

The authors declare they have no conflict of interests.

\section{References}

1 D.I.R. Geschichte des Deutschen IVF-Registers. 2016. Online: http:// www.deutsches-ivf-register.de/geschichte.php; last access: 28.01.2016

2 Kupka MS, van Rooij TNM, Happel L. Informationstechnologie als Werkzeug der Datengenerierung und Kommunikation im Deutschen IVFRegister - Das Deutsche IVF-Register 1996-2006. In: Felberbaum R, Bühler J, van der Ven H, Hrsg. Das Deutsche IVF-Register 1886-2006. 10 Jahre Reproduktionsmedizin in Deutschland. Heidelberg: Springer Medizin; 2007

3 Felberbaum $R$, Bühler $K$, van der Ven $H$. Das Deutsche IVF-Register 1996-2006. 10 Jahre Reproduktionsmedizin in Deutschland In: Felberbaum R, Bühler K, van der Ven H, Hrsg. Das Deutsche IVF-Register 1996-2006, 10 Jahre Reproduktionsmedizin in Deutschland. Heidelberg: Springer Medizin; 2007

4 D.I.R. Jahrbuch 2012 Deutsches IVF-Register. 2013. Online: http:// www.deutsches-ivf-register.de/perch/resources/downloads/ dirjahrbuch2012-d.pdf; last access: 27.08.2015

5 Bundesärztekammer. Richtlinien zur Durchführung der assistierten Reproduktion. Dtsch Ärztebl 1998; 95: 3166-3171

6 Enquete-Kommission Recht und Ethik der modernen Medizin. Schlussbericht. 2002: 1-280. Online: http://dip21.bundestag.de/dip21/btd/ 14/090/1409020.pdf; last access: 28.01.2016

7 Bundesärztekammer. (Muster)Richtlinie zur Durchführung der assistierten Reproduktion. Dtsch Ärztebl 2014; 111: 554

8 EIM Consortium. ESHRE's data collection: developments in online submission and in achieving greater coverage. Focus on Reproduction 2015; 9: 10-11

9 D.I.R. Jahrbuch 2013 Deutsches IVF Register. 2014. Online: http://www. deutsches-ivf-register.de/perch/resources/downloads/141117dir-jb 2013-deweb2.pdf; Stand 27.08.2015

10 Bundesärztekammer. (Muster)Richtlinie zur Durchführung der assistierten Reproduktion Novelle 2006. Dtsch Ärztebl 2006; 103: 13921403

11 Stammer H, Verres R, Wischmann T. Paarberatung und -therapie bei unerfülltem Kinderwunsch. Göttingen: Hogrefe Verlag; 2004

12 Alper M, Brinsden $P$, Fischer $R$ et al. Is your IVF programme good? Hum Reprod 2002; 17: 8-10

13 Kadi S, Wiesing U. Entscheidung ohne Information? Die Darstellung von Erfolg und Misserfolg der IVF und angrenzender Methoden auf den Webseiten deutscher IVF-Zentren. Geburtsh Frauenheilk 2015; 75: $1258-1263$

14 Sharif $K$, Afnan $M$. The IVF league tables: time for a reality check. Hum Reprod 2003; 18: 483-485 
15 D.I.R. Jahrbuch 2014 Deutsches IVF Register. 2015. Online: http://www. deutsches-ivf-register.de/perch/resources/downloads/dir-2014-d-1. pdf; last access: 17.02.2016

16 D.I.R. Satzung des Deutschen IVF-Registers e.V. (D.I.R) (unkonsolidiert) 15. November 2008 geändert am 2. Dezember 2013 zuletzt geändert (§12.2) am 4.12.2015 2015. Online: http://www.deutsches-ivfregister.de/perch/resources/downloads/satzung.pdf; last access: 28.01.2016

17 Felberbaum R, Dahnke W. Das Deutsche IVF-Register als Instrument der Qualitätssicherung und zur Beratung der Patienten. Gynäkologe 2000; 33: 800-811

18 HFEA. Choose a fertility clinic. 2015. Online: http://guide.hfea.gov.uk/ guide/; last access: 07.09.2015

19 Kentenich H, Tandler-Schneider A. Die Arztrolle in unterschiedlichen klinischen Kontexten: Ärztliche Beratung bei In-vitro-Fertilisation (IVF) und Präimplantationsdiagnostik (PID). Bundesgesundheitsblatt 2012; 55: 1144-1153

20 Revermann C, Hüsing B. Fortpflanzungsmedizin - Rahmenbedingungen, wissenschaftlich-technische Entwicklungen und Folgen: Endbericht zum TA-Projekt. Berlin: TAB; 2010

21 Bundesärztekammer. Weissbuch Anfang und Ende menschlichen Lebens. Köln: Deutscher Ärzte-Verlag; 1988
22 Soules MR. The in vitro fertilization pregnancy rate: let's be honest with one another. Fertil Steril 1985; 43: 511-513

23 Rjosk HK, Haeske-Seeberg H, Seeberg B et al. IVF und GIFT - Ergebnisse in Deutschland 1993. Fertilität 1995; 11: 48-54

24 Wiesing $U$. Medicine and Hubris - The Case of reproductive Medicine. In: Deltas C, Kalokairinou EM, Rogge S, eds. Progress in Science and the Danger of Hubris. Münster, New York, München, Berlin: Waxmann; 2006: 127-136

25 Wiesing U. Ethik, Erfolg und Ehrlichkeit. Zur Problematik der In-vitroFertilisation. Ethik Med 1989; 1: 66-82

26 Hölzle C, Wiesing $U$. Die In-vitro-Fertilisation - ein umstrittenes Experiment. Fakten - Leiden - Diagnosen - Ethik. Berlin: Springer; 1991

27 Diedrich K, Felberbaum R, Griesinger G et al. Reproduktionsmedizin im internationalen Vergleich. Wissenschaftlicher Sachstand, medizinische Versorgung und gesetzlicher Regelungsbedarf. Berlin: Friedrich Ebert Stiftung; 2008

28 Frühauf N, Bogs K. QS REPROMED - Das neue Qualitätssicherungsverfahren in der Reproduktionsmedizin. niedersächsisches ÄRZTEblatt 2014. Online: http://www.haeverlag.de/nae/n_beitrag.php?id=4492; last access: 28.01.2016

29 Simoes S, Bauer F, Schmahl FW. Register als Methode der Qualitätsförderung. Gesundheitswesen 2003; 65: 516-525 